$$
\begin{aligned}
& 320^{\prime} \\
& 7.27
\end{aligned}
$$

ORNL-3145

UC-80 - Reactor Technology

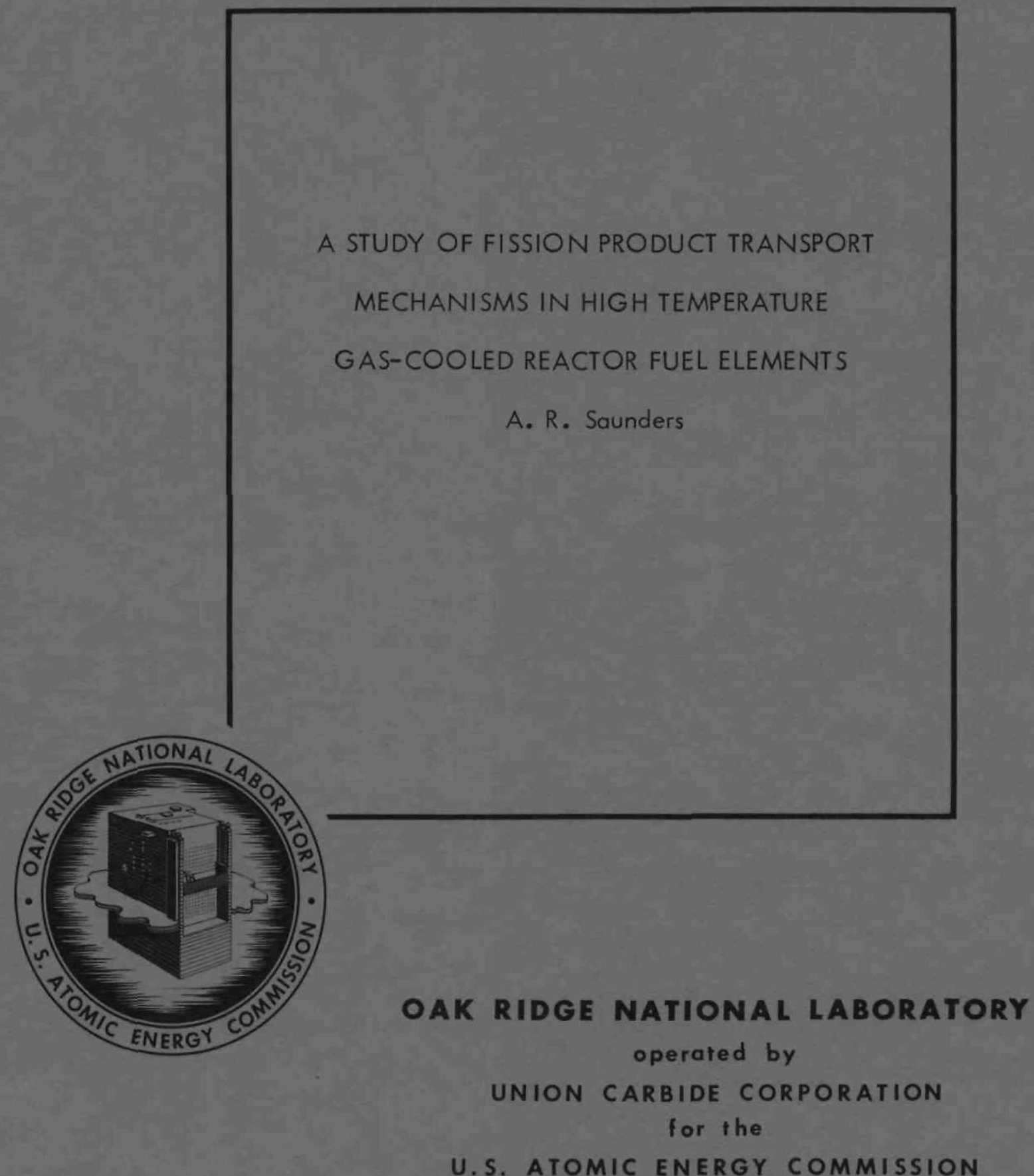




\section{Printed in USA. Price $\$ 0.75$. Avallable from the \\ Office of Technical Services \\ Deportment of Commerce \\ Woshington 25, D.C.}

\section{LEGAL NOTICE}

This report was prepared as an account of Government sponsored work. Neither the United Srates, nor the Commission, nor any person octing on behalf of the Commission:

A. Makes any warranty or represantation, expressed or impliod, with respect to the accurocy, completeness, or usefulness of the information contained in this report, or that the use of ony information, opporatus, method, or process disclosed in this report may not infringe privately owned rights; or

B. Assumes any liabilities with respect to the use of, or for domages resulting from the use of any information, apporatus, method, or pracess disclosed in this report.

As used in the above, "person acting on behalf of the Commission" includes any employee or contractor of the Cammission, of emplayee of such contractor, to the extent that such employee or contractor of the Commission, or emplayee of such contractor prepares, disseminates, or provides access to, any information pursuant to his employment or contract with the Commission, ar his employment with such contractor. 


\section{DISCLAIMER}

This report was prepared as an account of work sponsored by an agency of the United States Government. Neither the United States Government nor any agency Thereof, nor any of their employees, makes any warranty, express or implied, or assumes any legal liability or responsibility for the accuracy, completeness, or usefulness of any information, apparatus, product, or process disclosed, or represents that its use would not infringe privately owned rights. Reference herein to any specific commercial product, process, or service by trade name, trademark, manufacturer, or otherwise does not necessarily constitute or imply its endorsement, recommendation, or favoring by the United States Government or any agency thereof. The views and opinions of authors expressed herein do not necessarily state or reflect those of the United States Government or any agency thereof. 


\section{DISCLAIMER}

Portions of this document may be illegible in electronic image products. Images are produced from the best available original document. 
ORNL -3145

Contract No. W-7405-eng-26

REACTOR CHEMISTRY DIVISION

A STUDY OF FISSION PRODUCT TRANSPORT

MECHANISMS IN HIGH TEMPERATURE GAS-COOLED

REACTOR FUEL ELEMENTS

A. R. Saunders

DATE ISSUED

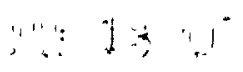

OAK RIDGE NATIONAL LABORATORY

Oak Ridge, Tennessee

operated by

UNION CARBIDE CORPORATION

for the

U.S. ATOMIC ENERGY COMMISSION 
7

. 
CONTENTS

Abstract . . . . . . . . . . . . . . . . . . . . . . . . 1
Introduction . . . . . . . . . . . . . . . . . . . . ${ }^{2}$
Experimental . . . . . . . . . . . . . . . . . . . . . 5

Rates of Diffusion for Fission Product Elements in Graphite Below $1000^{\circ} \mathrm{C}$. . . . . . . . . . 5

Rates of Diffusion for Fission Product Elements

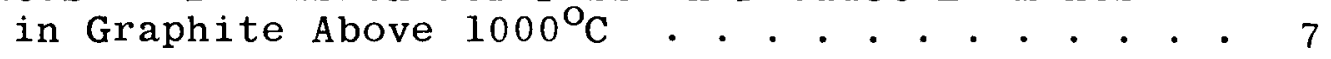

Discussion . • . . . . . . . . . . . . . . . . . 10

Survey of Earlier Experimental Work . . . . . . . . 10

Structure of Matrix and Mechanisms of Fission

Product Entry . . . . . . . . . . . . 13

Random Walk Theory of Solid State Diffusion . . . 15

Activation Energies for Fission Product Diffusion . 21

Mechanisms of Transport Above $1000^{\circ} \mathrm{C}$. . . . . . . 22

Chemical Reactions in Graphite . . . . . . . . . 24

References . . . . . . . . . . . . . . . . . 28 


\title{
A STUDY OF FISSION PRODUCT TRANSPORT \\ MECHANISMS IN HIGH TEMPERATURE GAS-COOLED \\ REACTOR FUEL ELEMENTS
}

A. R. Saunders

\begin{abstract}
The experimental work on the diffusion of fission products in ceramic matrices at high temperatures is reviewed and the possible mechanisms of mass transport are discussed. Preliminary data are given on diffusion in these systems.

It is shown that the rates of diffusion for fission products introduced by a recoil process into the moderator lattice can be correlated based on a random walk solid state diffusion model. An expression is derived for the coefficient of diffusion in terms of the lattice parameters giving the coefficients of diffusion for different atomic species as an exponential function of the atomic radii.

The possibility of other controlling mechanisms above $1000^{\circ} \mathrm{C}$ and the effect of carbide formation and other reactions is evaluated.
\end{abstract}




\section{INTRODUCTION}

Containment and removal of the fission products produced in a power reactor is an important problem in the operation of nuclear reactors. At lower temperatures metal cladding of the fuel elements is used to contain the fission products. Production of fuel element claddings impervious at the operating temperatures of the high temperature gas-cooled reactors is a much more difficult technical problem for which a satisfactory solution can be found only through an understanding of the mechanisms of mass transfer under reactor operating conditions.

Gas-cooled reactors can be operated at relatively high temperatures with thermal efficiencies exceeding those of fluid fuel reactors. The design concepts for fuel element operating temperatures of $2000^{\circ} \mathrm{F}$ or higher utilize ceramic matrices fabricated from graphite or refractory oxides containing the fuel as uranium carbide or oxide. 1 Examples of this approach are the Oak Ridge National Laboratory's HGCR-1 ${ }^{1}$ with fuel elements of 200-micron particles embedded in graphite, the Philadelphia ElectricGeneral Atomic-Bechtel Corp. HTGCR ${ }^{2}$ fueled with cylinders of graphite containing the ThC-UC fuel, sanderson and Porter-Alco Products Inc.'s Pebble Bed Reactor, PBR, ${ }^{3}$ as 
well as others.

The importance of a fission product in relation to the reactor operation and, hence, the need for its containment within the fuel is determined by its fission yield, half-life, gamma-activity and neutron absorption cross section. The fission products with long half-lives and high energy gamma-emissions, generated at a high yield, will cause the greatest radioactivity and contamination problems in the coolant gas stream to the extent that they escape from the fuel element.

Examination of a plot of fission yields of the products of U-235 fission ${ }^{4}$ shows that the elements with mass numbers of 85-105 and 130-150 have the highest fission yields. Fission yields for these products range from 2 to $6 \%$

Based on the amount of gamma-activity released as high energy decay products with long half-lives, decay chains 87-95, 129 and 131-143 are the most significant. 5,6 Examination of these fission chains indicates that $\mathrm{Rb}, \mathrm{Y}$, $\mathrm{Sr}, \mathrm{Zr}, \mathrm{Nb}$ are the most important radioactive products of chains 87-95, Sb, Te, and I of chain 129 and Sb, Te, I, $\mathrm{Xe}, \mathrm{Cs}, \mathrm{Ba}, \mathrm{Sr}, \mathrm{La}$ and Ce for chains 131-143.

Fission chains 147-161 produce rare earths with high neutron absorption cross sections. Rate of removal of 
these elements will influence the neutron economy of the reactor.

The fission products formed in an unclad ceramic fuel element will diffuse from the fuel into the gas stream by solid state diffusion. Fragments of sufficiently high kinetic energy will recoil into the moderator matrix. The fission products reaching the moderator will be transported through this matxix by pore, surface or solid state diffusion. The controlling mechanisms are different for each of these processes.

In this report the experimental data obtained on high temperature solid state and surface diffusion of fission product elements in graphite and some of the mechanisms controlling these processes will be discussed and the results compared with some of the earlier work. The experimental work is of exploratory nature and it was designed to study a number of idealized systems and obtain comparisons with earlier work giving an insight into the mechanisms controlling fission product transport in fuel element matrices. 


\section{EXPERIMENTAL}

Rates of Diffusion for Fission Product Elements in Graphite $\mathrm{Be} 1 \mathrm{w}=1000^{\circ} \mathrm{C}$

In this phase of the work, classical diffusion experiments were carried out utilizing an infinite plane geometry for measurements of the rates of diffusion of strontium and barium in graphite. The concentration gradients were determined by measurements of the gamma activity distribution in the samples.

Source matrix pellets of reagent grade BaO, Sro tagged with $\mathrm{Ba}^{133}$ and $\mathrm{Sr}^{85}$ were placed in contact with AGOT graphite pellets and held at constant temperature for several weeks in a furnace equipped with a Pyrovane temperature controller, passing a stream of helium gas over the diffusion couple during the experiment. A well-type scintillation counter was used to determine the gamma activities of source and matrix specimens before and after the experiment.

The coefficients of diffusion were evaluated using the solution of the diffusion equation for an infinite cylinder of unit cross section. ${ }^{7}$ The one-dimensional form of the diffusion equation is

$$
\partial \mathrm{C} / \partial \mathrm{t}=\mathrm{D} \partial^{2} \mathrm{C} / \partial \mathrm{x}^{2}
$$


where $\mathrm{C}$ is concentration of the diffusing species, $t$ is time, $D$ is coefficient of diffusion and $x$ is distance coordinate in the direction of the diffusion flux.

For the boundary conditions

$$
\begin{array}{lll}
\mathrm{C}=\mathrm{C}_{0} & \text { for } \mathrm{x}<0 & \text { at } \mathrm{t}=0 \\
\mathrm{C}=0 & \text { for } \mathrm{x}>0 & \text { at } \mathrm{t}=0
\end{array}
$$

the solution is

$$
C(x, t)=\left(C_{0} / 2\right) \operatorname{erfc}(x / 2 \sqrt{D t}) \text {. }
$$

Differentiation of this solution with respect to $x$ and substitution of the result into the flux equation gives

$$
J=-D(\partial C / \partial x)_{x=0}=C_{0} \sqrt{D} / 2 \sqrt{\pi t} .
$$

Integrating for a time period $t$ over a cross sectional area $A$ gives the total amount transferred as

$$
S=A \int_{0}^{t} J d t=A C_{0} \sqrt{D t / \pi}
$$

or solving for $D$

$$
\mathrm{D}=\mathrm{S}^{2} \pi / \mathrm{A}^{2} \mathrm{C}_{0}^{2} \mathrm{t}
$$

Using this equation the coefficient of diffusion can be determined for a known geometry from the initial source and final matrix compositions for diffusion over a fixed time period.

Experimental diffusion data obtained by this technique are given in Table $I$. An examination of the data indicates 
migration through the matrix by a relatively slow process.

Rates of Diffusion for Fission Product Elements in Graphite Above $1000^{\circ} \mathrm{C}$

Additional experimental data were obtained on the rates of transport of fission product elements at temperatures between 1000 and $1800^{\circ} \mathrm{C}$. At these temperatures the rates of migration are considerably higher and reactions with the graphite matrix are more likely to take place.

In order to facilitate these studies diffusion of one component was measured in a well defined geometry. The release rates were measured from an enclosed cylindrical source containing the diffusing oxide through the surrounding AGOT graphite matrix. The specimens used in the experiments were $1 / 2-i n$. o.d. by $3 / 4-i n$. cylinders with a .062-in. by 1/4-in. source. The choice of a 1:8 inside to outside diameter ratio allows use of the equations for diffusion through a plane sheet as a close approximation. 8

The source materials used in the experiments were $\mathrm{BaO}$, SrO, $\mathrm{Y}_{2} \mathrm{O}_{3}$ and $\mathrm{ZrO}_{2}$ with $\mathrm{Ba}^{133}, \mathrm{Sr}^{85}, \mathrm{Y}^{91}$ and $\mathrm{Hf}^{181}$ tracers. Selection of these elements gives a cross section of several of the important fission product decay chains. The enclosed hollow cylinders containing the source material were placed in a high temperature vacuum furnace 
and heated at constant temperature for a fixed time period. Measurement of the gamma activities of the cylinders before and after the experiment in a well-type scintillation counter allows determination of the rates of mass transport from the source through the porous graphite membrane. The experimental data obtained are given in Fig. 1 .

These data indicate two types of behavior for these systems. Either all activity gradually diffuses out from the source through the membrane or after some initial release of activity a more or less constant portion remains in the cylinders.

The effective coefficients of diffusion can be calculated from these experiments from the expression

$$
\left.\frac{d Q}{d t}=D A \frac{d C^{-}}{d r}\right\rfloor_{r=b}
$$

where $Q$ is the activity released over a time period $t$ from the cylinder, $D$ is the coefficient of diffusion, A the area through which diffusional transport takes place, b the outer radius of cylinder and $\mathrm{C}$ the concentration of the diffusant at point $r$ along the radius of the cylinder $r$. Assuming an average $\Delta C$ the coefficient of diffusion can be calculated when $\mathrm{dQ} / \mathrm{dt}$ is measured in a known geometry . 


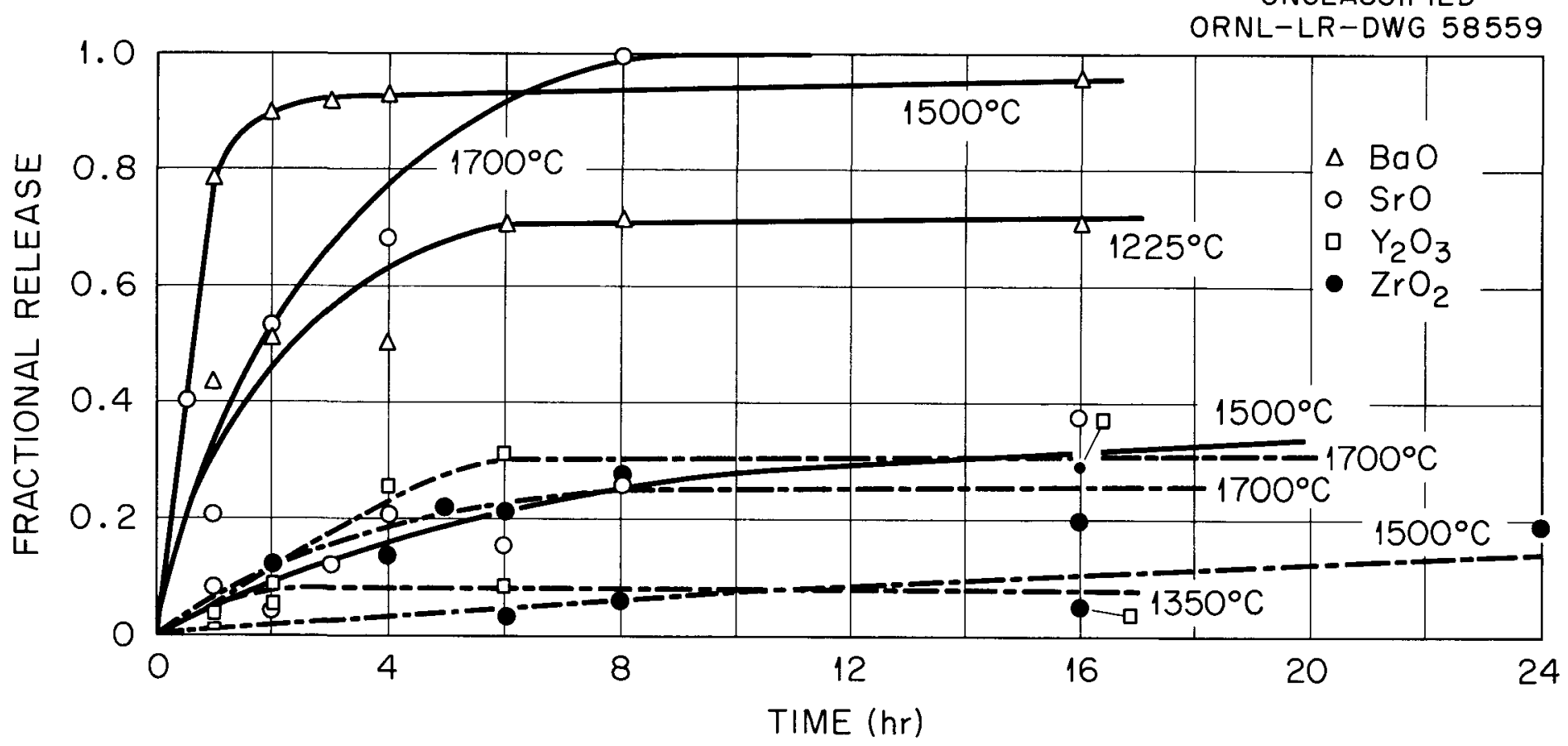

Fig. 1. Diffusion of Fission Element Oxides in Graphite Above $1000^{\circ} \mathrm{C}$. 
Values of the coefficients of diffusion $\mathrm{D}_{\text {eff }}$ and the energies of activation, $\Delta E$ derived from the experimental data are given in Table II. The considerably higher order of magnitude of the values indicates a mechanism of transport different from the diffusion process at lower temperatures.

\section{DISCUSSION}

Survey of Earlier Experimental Work

The measurement of fission product release rates from high temperature refractory fuel elements was the subject of several experimental investigations. ${ }^{5}$ Release of fission products was studied from uranium oxide and carbide alone or in combination with graphite and other moderator matrices.

Transport in the moderator matrix will be controlled by the processes transferring the diffusant into the matrix and the structure of the matrix. Transfer of diffusing fission products can take place either by (1) recoil of the high kinetic energy particles from the fuel into the matrix or (2) diffusion from the fuel. The relative importance of these two transfer processes will vary depending on the structure and size of the fuel particles. 
Table I. Results of Solid state

Diffusion Experiments

\begin{tabular}{|c|c|c|c|c|c|}
\hline $\begin{array}{c}\text { Source } \\
\text { Material }\end{array}$ & $\begin{array}{r}\mathrm{Co} \\
800^{\circ} \mathrm{C}\end{array}$ & $\begin{array}{l}\text { ficient } \\
\mathrm{cm}^{2} / \mathrm{sec} \\
850^{\circ} \mathrm{C}\end{array}$ & $\begin{array}{l}\text { of } \mathrm{Dif} \\
\times 10^{-1} \\
950^{\circ} \mathrm{C}\end{array}$ & ion & $\begin{array}{l}\text { Energy of } \\
\text { Activation, } \\
\text { kcal/g mole }\end{array}$ \\
\hline SrO & - & .882 & 1.03 & 41.60 & 52.1 \\
\hline $\mathrm{BaO}$ & .074 & - & - & - & - \\
\hline
\end{tabular}

Table II. Rates of Mass Transport in AGOT

Graphite Above $1200^{\circ} \mathrm{C}$

\begin{tabular}{lccc}
\hline Diffusant & $\begin{array}{c}\text { Temp. } \\
{ }^{\circ} \mathrm{C}\end{array}$ & $\begin{array}{c}\text { Effective Coefficient } \\
\text { of Diffusion } \\
\mathrm{D}_{\mathrm{E}} \mathrm{cm}^{2} / \mathrm{sec} \mathrm{x} \mathbf{1}^{-5}\end{array}$ & $\begin{array}{c}\text { Energy of } \\
\text { Activation, } \\
\mathrm{kcal} / \mathrm{g} \text { mole }\end{array}$ \\
\hline $\mathrm{BaO}$ & 1225 & 1.11 & 16.4 \\
$\mathrm{BaO}$ & 1500 & 3.72 & 119.8 \\
$\mathrm{SrO}$ & 1500 & 0.32 & 6.3 \\
$\mathrm{SrO}_{\mathrm{Y}} \mathrm{O}_{3}$ & 1700 & 2.93 & \\
$\mathrm{Y}_{2} \mathrm{O}_{3}$ & 1350 & 0.62 & 136.8 \\
$\mathrm{ZrO}_{2}$ & 1700 & 0.88 & \\
$\mathrm{ZrO}_{2}$ & 1700 & 0.024 &
\end{tabular}


A large portion of the fission products will become imbedded in the moderator lattice and this portion will be released by a slow solid state diffusion process. Above $1000^{\circ} \mathrm{C}$ mure rapid surface or grain boundary diffusion processes may also play a part in fission product transport in the moderator.

Largest portion of the experimental data on diffusion of fission products was accumulated in the temperature range between $1000-1900^{\circ} \mathrm{C}$. The group with North American Aviation, Inc. studied the release of fission products in this range for graphite impregnated with a molten uranium salt converted subsequently by heating in vacuum up to $1900^{\circ} \mathrm{C}$ into the carbide. Then the specimens were irradiated and the rates of fission product release were measured by heating in vacuum after decay of the short half-life activity.

Cubicciotti ${ }^{9}$ measured the rates of xenon release and Doyle ${ }^{10}$ determined the rates of release for most of the other important fission products in uranium carbide impregnated graphite. Young and Smith ${ }^{11,12}$ obtained more experimental data in the same area. Additional experimental work by Young ${ }^{13}$ furnished data on the fission product retention on deuteron bombardment at $1000-1950^{\circ} \mathrm{C}$. 
Diffusion of fission products from uranium impregnated graphite and magnesium oxide matrices at $1500^{\circ} \mathrm{C}$ to $3000^{\circ} \mathrm{C}$ was studied by Cowan and Orth $^{14}$ at the Los Alamos Scientific Laboratory.

More recently Findlay ${ }^{15}$ of the Atomic Energy Research Establishment, Harwe11, obtained experimental fission product diffusion data at $800^{\circ} \mathrm{C}$ on molten uranyl nitrate impregnated irradiated graphite after leaching out the fission products and uranium with nitric acid and measuring the rates of diffusion on the fission products retained in the graphite.

\section{Structure of Matrix and Mechanisms of Fission Product Entry}

The structure of the matrix in which diffusional transport takes place will have an important influence on the mechanism of the migration process. The structure of graphite ${ }^{16}$ can be described as an essentially random agglomerate of particles. The particles are composed of randomly arranged crystallites of about $150 \stackrel{\circ}{\mathrm{A}}$ cross section and up to $1000 \AA$ long. The pore volume of about $20-30 \%$ is distributed around the particles. Within the crystallites the graphite has a layer structure forming a two 
dimensional hexagonal mesh structure with each carbon atom bound to three other atoms. The distance between the carbon atoms in the layer is $1.42 \stackrel{\circ}{\mathrm{A}}$ and the separation between layers is 3.35 A. Alternate layers are displaced relative to each other somewhat. The bonds within the layers are covalent while the layers are held together by weaker van der Waals' forces.

The processes resulting in the introduction of the diffusing elements into the solid matrix will have an effect on the mechanisms by which diffusional transport of these species will take place. Fission product recoil entry into the graphite lattice can be interpreted based on the hot-zone model of nuclear recoil initiated reactions proposed by Harbottle and Sutin. ${ }^{17}$ The energy of the recoils is dissipated by producing displaced atoms and heating up to the melting point a small region of the matrix for a time period of the order of $10^{-11}$ sec. Some chemical reactions may have a chance to proceed during this period or the subsequent quenching period. Displacement of some atoms will produce vacancies or holes in the graphite crystal lattice and can introduce carbon atoms in interstitial positions. The fission fragments will be trapped in some locations in the lattice eventually. The 
resulting structure would contain fission product elements substituted in positions in the graphite lattice as we 11 as interstitially. In addition a number of more-or-less randomly distributed vacancies will be present in the graphite lattice. The radiation flux will produce similar effects in addition to the fission recoil penetration.

\section{Random Walk Theory of Solid state Diffusion}

Diffusional transport can be viewed as random walk of the diffusant through a matrix. Rayleigh demonstrated that using this model the diffusion equations can be derived and Zener ${ }^{18}$ showed that the coefficient of diffusion can be interpreted in terms of the statistical theory of reaction rates.

Let us assume that diffusion takes place along the $\mathrm{x}$-axis parallel to the crystal axis in jumps of length $\Delta x$ of equal probability in both $+x$ and $-x$ directions with a mean time $t$ between the jumps. Examining a segment of unit area for $\mathrm{n}(\mathrm{x}, \mathrm{t})$ atoms passing through the $\mathrm{x}$ plane at time $t$ the change for a time interval $\delta t$ will be

$$
\begin{aligned}
n(x, t+\delta t)-n(x, t)= & {[n(x+\Delta x, t)-n(x, t)+n(x-\Delta x, t)} \\
& -n(x, t)] \delta t / 2 t
\end{aligned}
$$


For $\delta t \rightarrow 0$ and $\Delta x \rightarrow 0$ the difference equation can be written as

$$
\partial \mathrm{n} / \partial \mathrm{t}=\mathrm{D}\left(\partial^{2} \mathrm{n} / \partial \mathrm{x}^{2}\right)
$$

with

$$
D=(\Delta x)^{2} / 2 t=\frac{1}{2}(\Delta x)^{2} R
$$

Then the coefficient of diffusion for different jump lengths can be expressed as

$$
\mathrm{D}=\frac{1}{2} \sum_{i} \mathrm{R}_{\mathbf{i}}\left(\Delta \mathrm{x}_{\mathrm{i}}\right)^{2}
$$

where $R_{i}$ is the rate at which an atom makes a particular jump i to the distance $\Delta \mathbf{x}_{i}$.

From the statistical theory of reaction rates of Eyring ${ }^{19}$ the expression for the mean rate of jumps can be given as

$$
\mathrm{R}=(\mathrm{kT} / \mathrm{h}) \mathrm{F} * / \mathrm{F}
$$

where $F^{*}$ is the partition function for the activated complex of the crystal lattice and diffusant atoms for the diffusing atom confined to a plane passing through the potential barrier and the two neighboring sites. No similar restraint is placed on the partition function F. The function $F$ can be expressed as

$$
\mathrm{F}=\mathrm{F}_{\mathrm{L}} \mathrm{F}_{1}^{*}
$$

where $F_{L}$ is the partition function of a single linear 
oscillator representing the dominant part of $F$ for vibration in a given site. For a linear oscillator $F_{L}$ can be expressed as

$$
\mathrm{F}_{\mathrm{L}}^{-1}=2 \sinh (\mathrm{h} v / 2 \mathrm{kT})
$$

which gives for the cases of interest as good approximation

$$
\mathrm{F}_{\mathrm{L}}^{-1}=\mathrm{h} v / \mathrm{kT}
$$

Hence the rate of jumps can be set equal to

$$
\mathrm{R}=(\mathrm{kT} / \mathrm{h}) \mathrm{e}^{-\Delta \mathrm{V} / \mathrm{kT}}=v \mathrm{e}^{-\Delta \mathrm{V} / \mathrm{kT}}
$$

where $k$ is the Boltzman constant, $h$ the Planck constant, $\mathrm{T}$ absolute temperature, $v$ the vibrational frequency of the atom held in a site in the lattice and $\Delta V$ the energy required to surmount the energy barrier between two successive positions in the lattice. For atoms held in a lattice by partially ionic forces this energy would be given by the Born-Lande equation 19

$$
\mathrm{U}_{0}=\frac{M Z_{1} Z_{2} e^{2}}{r}-\frac{B}{r^{n}}
$$

or for the lattice energy at the equilibrium distance in the crystal

$$
\mathrm{U}_{0}=\frac{\mathrm{M} \mathrm{Z}_{1} \mathrm{Z}_{2} \mathrm{e}^{2}}{\mathrm{r}_{0}}\left(1-\rho / \mathrm{r}_{0}\right)
$$

Here $r_{0}$ is the crystal radius, $Z$ the ionic charge, $M$ the Madelung constant which is related to the crystal structure 
parameters, e, electronic charge, $B, M$ and $\rho$ constants.

In these expressions the first term represents the electrostatic attraction and the second gives the repulsive energy due to overlapping of the valence bands. Combining the constants in Eq. (17) gives

$$
U_{0}=\frac{A Z_{1} Z_{2}}{r_{0}}\left(1-\rho / r_{0}\right)
$$

indicating that the lattice energy will be inversely proportional to the crystal radius.

For the atoms held in positions in the lattice the energy required for migration will be proportional to the energy barrier represented by the lattice forces. Hence

$$
\Delta F \propto \frac{A Z_{1} Z_{2}}{r_{0}}\left(1-\rho / r_{0}\right)
$$

and the coefficients of diffusion should be a function of the crystal radii of the intermediates or those of the diffusing atoms.

The final expression for the coefficient of diffusion can be written as

$$
D=\frac{1}{2} \sum_{i}\left(\Delta x_{i}\right)^{2} \frac{k T}{h} e^{-A Z_{1} Z_{2}\left(1-\rho / r_{0}\right) / k T r_{0}}
$$

Here the simplifying assumption is made that the rate of jumps will be the same in any position in the lattice. 
This may be only an approximation for a matrix containing a large number of fission fragments.

An examination of Fig. 2 showing the coefficients of diffusion for fission product recoils in graphite as given by Large and Walton ${ }^{15}$ indicates that these coefficients of diffusion are a function of the atomic radius of the species as indicated by Eq. (20). The agreement is good considering that the data cover a range of $10^{6}$ for the coefficients of diffusion. Xenon and cesium show the same relationship but the coefficients of diffusion are higher by a factor of $10^{3}$. These elements would be above the boiling point at $800^{\circ} \mathrm{C}$ and this may account for their increased mobilities in the lattice. The behavior of iodine which is also above the boiling point can be attributed to this and its relatively long half-life tellurium precursor. The relationship is valid using either the atomic or the ionic radii of the diffusing species. The atomic radii were preferred since the structure of the activated complexes is not known and the bonds may be partially covalent in the intermediate states. In addition the radii will be somewhat different for the different isotopes. This effect may be significant in estimation of the rates of diffusion for the species in different fission chains but the available data are not sufficiently accurate for 


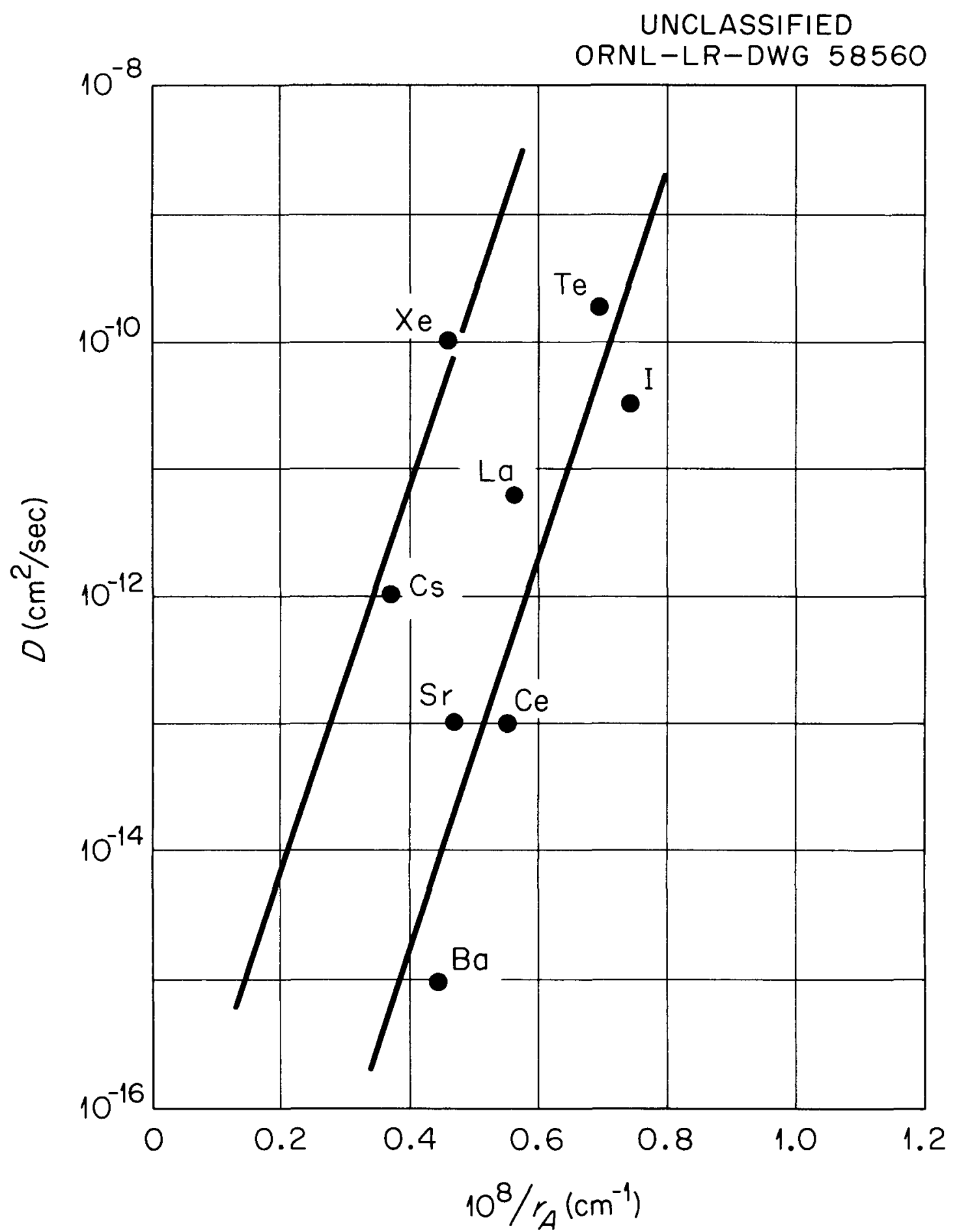

Fig. 2. Rates of Fission Product Diffusion in Graphite at $800^{\circ} \mathrm{C}$ as a Function of the Atomic Radii of the Diffusants. 
taking it into account at the present time.

The slope of the coefficients of diffusion versus atomic radii plot can be utilized to calculate the Madelung constant for a particular intermediate configuration by Eq. (20). This calculation based on a slope value of $3.85 \times 10^{4}$ and approximate values for the unknown constants from empirical lattice energy correlations yields a value of 95 for $M$. The value is of the correct order of magnitude for a structure where a diffusant atom would occupy a position in the graphite lattice. With a wider range of additional experimental data available this relationship can be further tested, the jump lengths and frequencies calculated.

Activation Energies for Fission Product Diffusion Further understanding of the mechanisms of fission product diffusion can be obtained through consideration of the energies of activation for diffusional transport. The available values for the energies of activation range from $20-100 \mathrm{kca} 1 / \mathrm{mole}$ for diffusion in graphite. Values given by Dienes ${ }^{21}$ for different mechanisms of selfdiffusion in graphite are somewhat higher. The calculated values for vacancy, direct interchange and interstitial diffusion are $119.4,90.4$ and $417.0 \mathrm{kcal} / \mathrm{mole}$ respectively. 
However it was observed that the activation energies for chemical diffusion are usually lower than those for selfdiffusion. Johnson ${ }^{22}$ interpreted this as an indication that less work is required to produce a lattice vacancy adjacent to a solute or impurity atom at a particular lattice site. This in combination with the enhanced vacancy formation rate under irradiation would account for these lower values for the energies of activation for fission product diffusion in graphite or other matrices.

Mechanisms of Transport Above $1000^{\circ} \mathrm{C}$

At temperatures above $1000^{\circ} \mathrm{C}$ fission product transport is controlled by processes that are different from the rate controlling steps at lower temperatures. Examination of the diffusion data obtained at these temperatures indicates diffusion combined with chemical reactions for $Y$ and Zr. The comparatively low values obtained for the activation energies from the data indicate that diffusional transport may take place at least partially on the free surfaces of the crystallites rather than through the crystal lattice.

As Fig. 3 indicates the data for the effective coefficients of diffusion for all the systems studied can be correlated as a function of the reduced temperature $T / T_{M}$. 


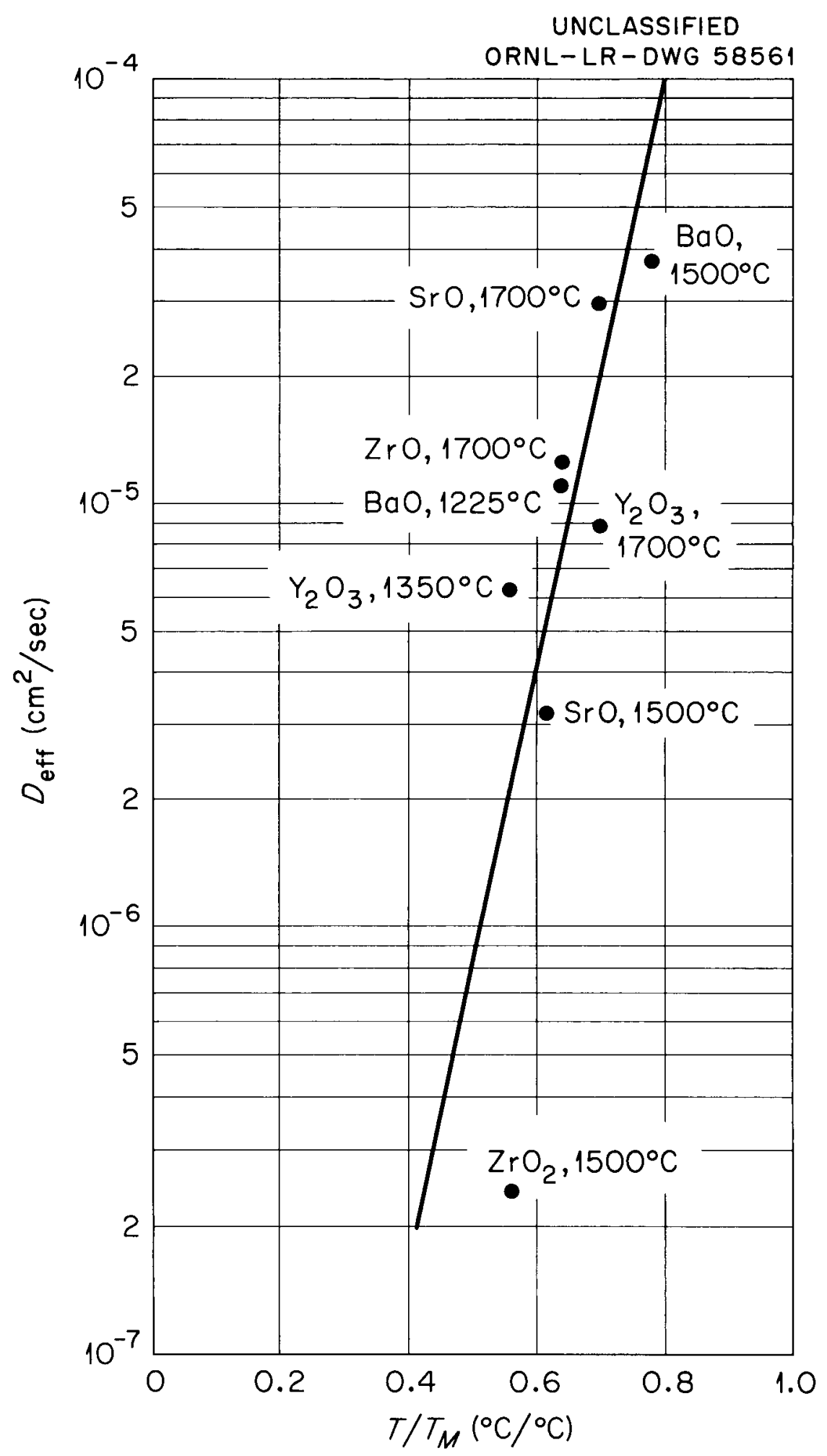

Fig. 3. Diffusion of Metal Oxides in Graphite as a Function of the Melting Point. 
Diffusional transport can be described in this system as a two dimensional random walk through the surface imperfections. The mobility of the diffusing species will be proportional to the $\mathrm{T} / \mathrm{T}_{\mathrm{M}}$ ratio or the kinetic energy of the migrating species.

\section{Chemical Reactions in Graphite}

In addition to the aspects of fission product diffusion already discussed, the effects of chemical reactions between the diffusants and matrix should be also examined.

Graphite can form intercalation and residue compounds with a large number of elements and their salts. Recent work by Croft, ${ }^{23}$ Hennig, ${ }^{16}$ Rudorff ${ }^{24}$ and others indicates that chemical species that can act as electron acceptors or donors will form ionic or covalent bonds with graphite. Since the conduction and valence bands are separated by a narrow energy gap with some overlap between the two bands a small change in the concentration of holes or electrons can have a comparatively large effect on the electrical properties of the graphite. X-ray crystal structure studies on these intercalation or interstitial compounds indicate that the intercalated substance is held between the graphite planes in units that have symmetries somewhat similar to the structure of the graphite planes with appreciably 
larger spacings. The residual compounds appear to be atoms held near imperfections in the graphite structure. Although most of the intercalation compounds decompose below the temperatures a nuclear fuel element is exposed to, some exhibit surprising stability. Residual compounds ${ }^{16}$ can be stable at temperatures up to $2000^{\circ} \mathrm{C}$ in polycrystalline graphite.

Formation of carbides by reactions between fission products and graphite becomes increasingly important at high temperatures. Since the available thermodynamic data for metal carbides are somewhat incomplete the heats and entropies of formations were estimated for the carbides of several rare earths and noble metals appearing as fission products. The values for the heats of formation were estimated from an empirical relationship between the thermodynamic properties of homologous series and the entropies of formation were obtained by Latimer's method 25 from the partial entropies of the elements. Since heat capacity data are mostly unavailable the relationship

$$
\Delta F_{f T}=\Delta H_{f} 298^{\circ} \mathbf{K}-T \Delta S_{f} 298^{\circ} \mathbf{K}
$$

was used to calculate the free energies of the carbide formation reaction from the elements. Assumption of no change in the heat capacities should give reliable free 
energy values for the systems considered.

The free energy values given in Table III indicate that formation of hard metal and rare earth carbides is most likely but the alkali earth and even the noble metals may form carbides at sufficiently high temperatures. A comparison with fission product diffusion data indicates a similar trend in the quantities of these elements retained in graphite matrices. The alkali earth elements are not retained in the graphite matrix but the carbides of these elements have melting points below $2000^{\circ} \mathrm{C}$ and their mobility in the matrix should be considerably higher than those of the refractory carbides. 
Table III. Free Energies, Heats of Formation and Standard

Entropies of the Carbides of Fission Products

\begin{tabular}{|c|c|c|c|c|c|c|}
\hline Compound & $\begin{array}{l}-\Delta H_{f} 298{ }^{O} \mathbf{K} \\
\mathrm{kcal} / \mathrm{mole}\end{array}$ & $\begin{array}{c}\Delta_{\mathrm{f}} 298^{\circ} \mathrm{K} \\
\mathrm{cal} / \mathrm{deg} \mathrm{mole}\end{array}$ & ${ }_{298}^{-\Delta F_{f T}} \mathbf{f}$ & $\begin{array}{l}\mathrm{kcal} / \\
1073\end{array}$ & $\begin{array}{r}\text { ole at } \\
1473\end{array}$ & 1873 \\
\hline $\mathrm{SrC}_{2}{ }^{\mathrm{a}}$ & 10 & 3.7 & 11.1 & 14 & 15.5 & 16.9 \\
\hline $\mathrm{BaC}_{2}{ }^{\mathrm{b}}$ & 5 & 3.4 & 6 & 8.6 & 10 & 11.4 \\
\hline $\mathrm{YC}_{2}{ }^{\mathrm{a}}$ & 23 & 7.5 & 25.2 & 31 & 34 & 37 \\
\hline $\mathrm{LaC}_{2} \mathrm{a}$ & 23 & 3.4 & 24 & 26.6 & 28 & 29.4 \\
\hline $\mathrm{CeC}_{2}{ }^{\mathrm{a}}$ & 24 & 3.4 & 25 & 27.6 & 29 & 30.4 \\
\hline $\operatorname{PrC}_{2}{ }^{a}$ & 26 & 3.4 & 27 & 29.6 & 31 & 32.4 \\
\hline $\mathrm{ZrC} \mathrm{C}^{\mathrm{b}}$ & 45 & 8.5 & 47.5 & 54.1 & 57.5 & 60.9 \\
\hline $\mathrm{Mo}_{2} \mathrm{C}^{\mathrm{b}}$ & -4.2 & 2.4 & 11.3 & 30.0 & 39.6 & 49.2 \\
\hline $\mathrm{Ru}_{2} \mathrm{C}^{\mathrm{C}}$ & -17 & 7.3 & -14.9 & -9.2 & -6.3 & -3.3 \\
\hline$R h_{3} C^{C}$ & -50 & 17.7 & -44.8 & -31 & -23.9 & -16.9 \\
\hline $\mathrm{Pd}_{3} \mathrm{C}^{\mathrm{C}}$ & -54 & 17.9 & -48.7 & -34.8 & -27.6 & -20.5 \\
\hline
\end{tabular}

a. Estimated from lattice parameters

b. High Temperature Technology, ed. by I. E. Campbell, John Wiley and Sons, Inc., New York, 1956.

c. Estimated by homologous series method. (0. Kubaschewski and E. L. Evans, Metallurgical Thermochemistry. John Wiley and Sons, Inc., New York, 1956.) 


\section{REFERENCES}

1. The ORNL Gas-Cooled Reactor Advanced Concepts, ORNL-2510 (Sept. 18, 1958).

2. High Temperature Gas-Cooled Graphite-Moderated Power Station. General Atomics, GA-593, GACP-595, GA-598, (Nov. 1958).

3. Sanderson and Porter, Design and Feasibility study of a Pebble Bed Reactor steam Power Plant, S \& p 1963A, vol 1 (May 1958).

4. S. Glasstone and M. C. Edlund, The Elements of Nuclear Reactor Theory (67, Van Nostrand Company, Inc., New York, 1952).

5. T. A. Lane et al., A Study of Problems Associated with Release of Fission Products from Ceramic Fuels in Gas-Cooled Reactors, ORNL-2851 (Oct. 27, 1959).

6. T. O. Blomeke and M. F. Todd, Uranium-235 FissionProduct Production as a Function of Thermal Neutron Flux, Irradiation Time, and Decay Time, Part 1, Vol. 1, ORNL-2127 (NOV. 12, 1958).

7. W. Jost, Diffusion in Solids, Liquids, Gases, Academic Press Inc., New York, 1960.

8. T. Crank, The Matematics of Diffusion, Oxford University Press, London, 1957.

9. D. Cubicciotti, The Diffusion of Xenon from Uranium Carbide Impregnated Graphite at High Temperatures, NAA-SR-194 (Oct. 13, 1952).

10. L. B. Doyle, High Temperature Diffusion of Individual Fission Elements from Uranium Carbide Impregnated Graphite, NAA-SR-255 (Sept. 11, 1953).

11. C. A. Smith and C. T. Young, Diffusion of Fission Fragments from Uranium Impregnated Graphite, NAA-SR-72, (May 4, 1951).

12. C. T. Young and C. A. Smith, Preliminary Experiments on Fission Product Diffusion from Uranium Impregnated Graphite in the Range $1800^{\circ}-2200^{\circ} \mathrm{C}, \mathrm{NAA}-\mathrm{SR}-232$ (June 17, 1953). 
13. C. T. Young, High Temperature Diffusion of Individual Fission Products from Small Uranium Impregnated Graphite Samples under Deuteron Bombardment, NAA-SR-247 (Sept. 1, 1953).

14. G. A. Cowan and C. T. Orth, Diffusion of Fission Products at High Temperatures from Refractory Matrices. Second United Nations International Conference on the Peaceful Uses of Atomic Energy. A/Conf.15/P/613 (June 1958).

15. N. R. Large and G. N. Walton, Migration of Non-Gaseous Fission Products through Graphite, AERE C/M 346 (1958).

16. G. R. Hennig, "Interstitial Compounds of Graphite," $\mathrm{p} 125$ in Progress in Inorganic Chemistry, Vol. 1. Interscience Publishers, Inc., New York, 1959.

17. G. Harbottle and N. Sutin, J. Phys. Chem. 62, 1344 (1958).

18. C. Zener, "Theory of Diffusion," p 289 in Imperfections in Nearly Perfect Crystals, ed. by W. Shockley et al., John Wiley and Sons, Inc., New York, 1952.

19. S. Glasstone, K. T. Laidler and Henry Eyring, The Theory of Rate Processes, McGraw-Hill Book Co., Inc., New York, 1941.

20. T. C. Waddington, "Lattice Energies and Their Significance in Inorganic Chemistry," in Advances in Inorganic and Radiochemistry, Vol. I, Academic Press Inc., New York, 1959 .

21. G. T. Dienes, Jour. of Applied Phys., 23, 1194 (1952).

22. R. P. Johnson, Physical Review, $\underline{\underline{56}}, 814$ (1939).

23. R. C. Croft, J.Appl. Chem. 2, 557 (1952).

24. W. Rudorff, "Graphite Intercalation Compounds," p 224 in Advances in Inorganic and Radiochemistry, Vol. I. Academic Press, Inc., New York, 1959.

25. O. Kubaschewski and E. L. Evans, Metallurgical Thermochemistry. John Wiley and Sons, Inc., New York, 1956. 
$\bullet$ 


$$
\text { ORNL-3145 }
$$

UC-80 - Reactor Technology

TID-4500 (16th ed.)

\section{INTERNAL DISTRIBUTION}

1. Biology Library

2. Reactor Division Library

3. ORNL - Y-12 Technical Library, Document Reference Section

4-5. Central Research Library

6-26. Laboratory Records Department

27. Laboratory Records, ORNL R.C.

28. C. E. Center

29. A. M. Weinberg

30. J. P. Murray $(K-25)$

31. R. G. Jordan $(Y-12)$

32. J. A. Swartout

33. G. E. Boyd

34. W. R. Grimes

35. R. B. Briggs

36. D. S. Billington

37. F. F. Blankenship

38. A. L. Boch

39. J. H. Frye, Jr.

40. H. G. MacPherson

41. J. C. White

42. W. D. Manly

43. C. H. Secoy

44. E. G. Boh 1mann

45. R. A. Charpie

46. F. L. Culler

47. W. H. Jordan

48. M. T. Kelley

49. I. A. Lane

50. H. F. McDuffie

51. M. J. Skinner

52. A. H. Sne 11

53. E. H. Taylor

54. G. M. Watson

55. C. E. Winters

56. G. C. Warlick

57. E. L. Compere

58. J. C. Griess

59. G. H. Jenks
60. R. B. Korsmeyer

61. H. C. Savage

62. M. Blander

63. S. Cantor

64. J. H. Shaffer

65. M. J. Kelly

66. C. J. Barton

67. W. L. Marshall

68. C. F. Baes

69. R. E. Thoma

70. R. A. Strehlow

71. R. B. Evans, III

72. G. W. Keilholtz

73. W. E. Browning

74. W. T. Rainey

75. L. G. Overholser

76-78. A. R. Saunders

79-104. Lois Curry

105. F. Daniels (consultant)

106. F. T. Miles (consultant)

107. F. T. Gucker (consultant)

108. Leo Brewer (consultant)

109. J. E. Ricci (consultant)

110. D. G. Hill (consultant)

111. G. W. Morey (consultant)

112. H. Eyring (consultant)

113. M. G. Fontana (consultant)

114. R. M. Fuoss (consultant)

115. N. Hackerman (consultant)

116. H. S. Harned (consultant)

117. H. Insley (consultant)

118. E. A. Mason (consultant)

119. T. N. McVay (consultant)

120. G. Scatchard (consultant)

121. T. F. Young (consultant)

122. J. S. Dahler (consultant)

123. J. W. Cobble (consultant)

124. P. H. Emmett (consultant) 
EXTERNAL DISTRIBUTION

125. Division of Research and Development, AEC, Washington

126. Division of Research and Development, AEC, ORO

127. Division of Reactor Development, AEC, Washington

128. Division of Reactor Development, AEC, ORO

129-732. Given distribution as shown in TID-4500 (16th ed.) under Reactor Technology category (75 copies - OTS) 